\title{
Оптимизация методики получения рекомбинантных двухдоменных лакказ
}

\author{
® 2019 Трубицина Л.И., Трубицин И.В., Лисов А.В. \\ Институт биохимии и физиологии микроорганизмов им. Г.К. Скрябина РАН - \\ обособленное подразделение ФГБУН «Федеральный исследовательский центр «Пущинский научный \\ иентр биологических исследований Российской академии наук», Пущино
}

Поступила в редакцию 15.11.2019 г.

DOI: $10.17308 /$ sorpchrom.2020.20/2386

Лакказы (К.Ф. 1.10.3.2) - ферменты из семейства медьсодержащих оксидаз, активный центр которых содержит 4 атома меди. Лакказы способны окислять широкий спектр органический и неорганических соединений. Ферменты данного класса используют в биотехнологических целях (в целлюлозно-бумажной, текстильной, пищевой промышленности). В структурном отношении лакказы подразделяют на 2 группы: двухдоменные (2д) и трёхдоменные (3д) ферменты. Характерные особенности 2д лакказ - устойчивость к специфичным ингибиторам семейства медьсодержащих оксидаз, а также высокая термостабильность. Окислительно-восстановительный потенциал 2д лакказ ниже потенциала 3д ферментов. Однако он может быть повышен благодаря использованию редоксмедиаторов. Высокая термостабильность и устойчивость к действию ингибиторов - важные критерии отбора ферментов для нужд биотехнологии. Также важным критерием для биотехнологически значимых ферментов является стоимость их производства. Если получение фермента требует значительных затрат, а выход конечного продукта низок, то производство фермента нецелесообразно.

Поэтому целью данной работы является оптимизация процесса получения двухдоменных рекомбинантных лакказ, экспрессируемых гетерологично в штамме Escherichia coli, с расчетами стоимости конечного продукта (на примере ферментов SgfSL, SvSL и SaSL, полученных в нашей лаборатории). Ранее три рекомбинантные двухдоменные лакказы были клонированы и экспрессированы в штамме Escherichia coli M15 (pRep4). В данной работе мы исследовали влияние различных факторов на максимальный выход лакказ: влияние ионов меди, концентрации индуктора, условий культивирования, оптической плотности культуры, и других условий. Было показано, что оптимальная концентрация ионов меди составляет 1 мМ, а оптимальная концентрация индуктора ИПТГ составляет 0,1 мМ (при этом отсутствует эффект агрегирования и наблюдается высокий выход ферментов). Мы подтвердили выводы коллег о том, что для получения лакказ, максимально насыщенных ионами меди, необходимы микроаэробные условия культивирования. Без стадии микроаэробного роста удельная активность очищенных ферментов снижается в 2 раза. Было обнаружено, что слишком высокая скорость перемешивания клеток при индукции синтеза лакказ приводит к агрегации ферментов. Скорость перемешивания, при которой лакказы не агрегируют, составляет 50-100 об/мин.

Выводы: был разработан и оптимизирован процесс получения двухдоменных бактериальных рекомбинантных лакказ. Максимальный выход ферментов составил 180 мг белка с литра среды. Фермент имел низкую себестоимость (16-32 евро за 1 г белка).

Ключевые слова: двухдоменная лакказа, фермент, очистка, аффинная хроматография.

\section{Введение}

Лакказы - ферменты из семейства оксидоредуктаз, содержат четыре атома меди в активном центре. Они катализируют реакцию восстановления кислорода до воды, окисляя при этом широкий спектр органических и неорганических соединений. Лакказы распространены у бактерий, грибов, высших растений [1,2], идентифицированы у водорослей [3], лишайников [4]. Лакказы выполняют разнообразные биологические функции: грибные лакказы участвуют в деградации лигнина, а также 
детоксификации продуктов разложения лигнина [5], участвуют в морфогенезе (формирование плодового тела гриба, формирование ризоморфов). Лакказы растений участвуют в биосинтезе лигнина [6]. Лакказы бактериального происхождения участвуют в морфогенезе и споруляции, также способны деградировать фенольные подструктуры лигнина [7,8]. Благодаря низкой субстратной специфичности, высокой окислительной способности и высокой стабильности лакказ ферменты активно используются в различных биотехнологических процессах (в пищевой промышленности при производстве соков и вин [9], в текстильной промышленности при детоксификации сточных вод производства [10], в целлюлозно-бумажной промышленности при производстве бумаги [11] и т.д.). В структурном отношении лакказы подразделяют на ферменты с двумя и тремя структурно-функциональными доменами. Двухи трёхдоменные лакказы отличаются стабильностью, окислительным потенциалом, а также устойчивостью к ингибиторам. Чаще более стабильны и устойчивы к действию ингибиторов двухдоменные лакказы, однако трёхдоменные ферменты обладают более высоким окислительным потенциалом. Окислительно-восстановительный потенциал двухдоменных лакказ возможно повысить использованием медиаторов, а высокая термостабильность а также устойчивость к действию ингибиторов являются важными критериями отбора ферментов для нужд биотехнологии. Очень важным критерием для использования ферментов является себестоимость их получения. Если получение фермента требует значительных затрат, а выход конечного продукта низкий, то производство фермента нецелесообразно. Поэтому целью данной работы стала оптимизация методики получения двухдоменных рекомбинантных лакказ, экспрессированных гетерологично в штамме Escherichia coli, с расчётом себестоимости конечного продукта (на примере ферментов SgfSL, SvSL, и SaSL, ранее полученных в нашей лаборатории).

\section{Эксперимент}

Гены двухдоменных лакказ из бактерий Streptomyces viridochromogenes ВКМ Ac-629, S. griseoflavus ВКМ Ac-993, S. anulatus ВКМ Аc-728 (номера нуклеотидных последовательностей в базе данных NCBI: JX393082.1, KP941125.1, NZ_CM003601.1:7516190-7517239) ранее были клонированы в экспрессионный вектор pQE-30 $[12,13,14]$. Штаммы бактерий были получены из Всероссийской коллекции микроорганизмов (http://www.vkm.ru/index.htm). Для продукции трёх рекомбинантных лакказ векторы с геном-вставкой были трансформированы в клетки E.coli M15 (pRep4). Затем 2-3 колонии трансформантов вносили в $5 \mathrm{~cm}^{3}$ жидкой среды LB (г/дм ${ }^{3}:$ триптон - 10, дрожжевой экстракт $\left.-5, \mathrm{NaCl}-10\right)$, содержащей антибиотики

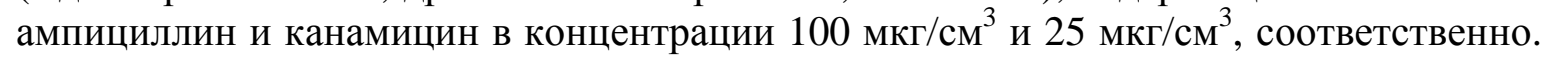
Клетки инкубировали 16 ч при $37^{\circ} \mathrm{C}$ и 150 об/мин. Ночную культуру в объёме 1 мл вносили в $200 \mathrm{~cm}^{3}$ среды LB с антибиотиками и культивировали до достижения клетками оптической плотности при 600 нм 1.0 или 1.4. Затем в среду вносили индуктор ИПТГ в концентрации $0.1 \mathrm{мM}$ или 1 мМ и ионы меди в концентрации $0.5 \mathrm{mM}$ или 1 мМ. Дальнейшее культивирование проводили при $20^{\circ} \mathrm{C}$ и 50,100 или 150 об/мин в течение 18 ч. Затем колбы снимали с качалки и оставляли при $25^{\circ} \mathrm{C}$ без перемешивания на 24 ч. Клетки центрифугировали 20 мин $10000 \mathrm{~g}$ при $4^{\circ} \mathrm{C}$, ресуспендировали в $20 \mathrm{~cm}^{3}$ буфера 1 (20 мМ Трис-HCl, $0.5 \mathrm{M} \mathrm{NaCl}, 1 \mathrm{MM}$ имидазол, pH 7.4) и разрушали на дезинтеграторе. Клеточный лизат центрифугировали 30 мин $20000 \mathrm{~g}$ при $4^{\circ} \mathrm{C}$. Надосадочную фракцию наносили на 5 мл колонку HiTrap c Ni-cефарозой (GE Healthcare, USA) уравновешенную буфером 1, затем промывали буфером 1 и буфером 2 (20 мМ Трис-HCl, $0.5 \mathrm{M} \mathrm{NaCl}, 50$ мМ имидазол, $\mathrm{pH}$ 7.4). Элюцию фер- 
мента проводили буфером 3 (20 мМ Трис- $\mathrm{HCl}, 0.5 \mathrm{M} \mathrm{NaCl}, 300$ мМ имидазол, $\mathrm{pH}$ 7.4). Фракции, содержащие лакказу, были окрашены в синий цвет.

Осадок ресуспендировали в буфере 1 с добавлением детергента Triton X-100, центрифугировали образец 30 мин $20000 \mathrm{~g}$ при $4^{\circ} \mathrm{C}$. После центрифугирования надосадочную фракцию наносили на колонку, уравновешенную буфером 1 с добавлением Triton X-100. Очистку проводили согласно схеме, описанной выше. Для подтверждения чистоты препаратов проводили электрофорез в полиакриламидном геле в денатурирующих условиях.

Концентрацию белков определяли спектрофотометрически с использованием коэффициента молярной экстинкции при 280 нм (коэффициенты экстинкции для каждого из ферментов определяли при помощи программы Vector NTI).

\section{Обсуждение результатов}

Для высокого выхода лакказ в ходе продукции рекомбинантным продуцентом необходимо учитывать ряд факторов: продолжительность культивирования, концентрацию индуктора, наличие микроаэробных условий, концентрацию ионов меди в среде культивирования. В данной работе влияние каждого из этих факторов было рассмотрено и установлены оптимальные условия для максимального выхода активного фермента.

Влияние ионов меди. Лакказа - медьсодержащий фермент, требующий наличия ионов меди при рекомбинантной продукции фермента. Ранее было установлено, что отсутствие ионов меди в процессе гетерологичной продукции фермента приводило к неправильному фолдингу лакказы. Диализ фермента с неправильным фолдингом против буферного раствора с ионами меди приводил к неполному насыщению активного центра медью и отсутствию высокой активности фермента [15]. В данной работе в процессе индукции вносили ионы меди в среду культивирования. Было показано, что оптимальная концентрация ионов меди - 1 мМ. При более низкой концентрации активность была ниже, более высокая концентрация не влияла на повышение выхода активного фермента.

Влияние концентрации индуктора. Индуктор лакказ, используемый в данной гетерологичной системе экспрессии - изопропил- $\beta$-D-1-тиогалактопиранозид (ИПТГ). Установлено, что при концентрации 1мМ ИПТГ в некоторых случаях (лакказа SvSL и SgfSL) наблюдалось агрегирование лакказ, в надосадочной фракции оставалось небольшое количество фермента. Рефолдинг требует дополнительных затрат и зачастую даёт низкий выход активного фермента. Поэтому использование высокой концентрации ИПТГ не целесообразно. При концентрации ИПГТ 0.1 мМ эффект агрегирования отсутствовал и наблюдался высокий выход лакказ.

Микроаэробные условия. Ранеe Durao с соавторами продемонстрировал, что для оптимального насыщения ионами меди рекомбинантных ферментов необходимо создать микроаэробные условия в процессе индукции [15]. После культивирования клеток с индуктором и ионами меди необходимо на сутки оставить клетки без перемешивания. В таком случае проницаемость клеточной стенки для ионов меди возрастает, и клетка аккумулирует ионы меди в концентрации до 80 крат превышающие концентрацию ионов меди в аэробных условиях, и лакказа максимально насыщается ионами меди. В данном исследовании мы подтвердили заключение коллег. Без стадии микроаэробных условий удельная активность очищенного фермента снижалась в 2 раза.

Оптическая плотность клеток до внесения индуктора. Внесение индуктора происходит по достижении клеток определённой оптической плотности. Мы растили

Tрубицина и др. / Сорбционные и хроматографические процессы. 2020. Т. 20. № 1. С. 109-114 
клетки до достижения ими оптической плотности при 600 нм равной 1.0 и 1.4. При этом разницы в конечном выходе лакказ не наблюдалось.

Другие условия. Установлено, что слишком высокая скорость перемешивания клеток в процессе индукции синтеза ферментов приводила к агрегированию лакказ. Скорость качалки, при которых лакказа не агрегировала - 50-100 об/мин.

Таким образом, была разработана следующая схема очистки и получения рекомбинантных лакказ. Ночную культуру в объёме 1 мл инокулировали в $200 \mathrm{~cm}^{3}$ среды LB, культивировали при $37^{\circ} \mathrm{C} 150$ об/мин до достижения клетками оптической плотности 1.0. Затем вносили $1 \mathrm{mM} \mathrm{CuSO} 4$ и $0.1 \mathrm{мM} \mathrm{ИПТГ,} \mathrm{дальнейшую} \mathrm{инкубацию}$ проводили при $20^{\circ} \mathrm{C} 100$ об/мин в течение 18 ч. После этого клетки инкубировали при $25^{\circ} \mathrm{C}$ без перемешивания 24 ч. Затем клетки центрифугировали 20 мин $10000 \mathrm{~g}$ при $4^{\circ} \mathrm{C}$, разрушали на дезинтеграторе, центрифугировали 30 мин $20000 \mathrm{~g}$ при $4^{\circ} \mathrm{C}$. Надосадок наносили на колонку с $\mathrm{Ni}$-сефарозой и проводили одностадийную очистку ферментов благодаря наличию у рекомбинантных белков гистидинов на $\mathrm{N}$ концевой части. Осадок ресуспендировали в буфере с детергентом, центрифугировали пробы, и далее проводили одностадийную очистку лакказ, перешедших в надосадочную фракцию. В таблице 1 представлен выход трёх рекомбинантных лакказ, полученных по описанной схеме.

Таблица 1. Выход рекомбинантных лакказ

\begin{tabular}{|c|c|c|c|c|c|}
\hline \multirow{2}{*}{ Белок } & \multicolumn{3}{|c|}{ Выход, мг со $100 \mathrm{~cm}^{3}$ среды } & \multirow{2}{*}{$\begin{array}{l}\text { Средний вы- } \\
\text { ход, мг/дм }{ }^{3}\end{array}$} & \multirow{2}{*}{$\begin{array}{c}\text { Стоимость реактивов для } \\
\text { получения } 1 \text { г белка }\end{array}$} \\
\hline & 1 опыт & 2 опыт & 3 опыт & & \\
\hline SvSL & 13.91 & 15.36 & 14.03 & 144.3 & $709 \mathrm{p}$ \\
\hline SgfSL & 8.65 & 8.04 & 10.35 & 90.1 & $1135 \mathrm{p}$. \\
\hline $\mathrm{SaSL}$ & 17.5 & 17.67 & 18.83 & 180 & $568 \mathrm{p}$. \\
\hline
\end{tabular}

Наибольший выход двухдоменной лакказы, ранее полученной при экспрессии в штамме E.coli, составил 40-50 мг с 1 дм $^{3}$ среды [16]. Таким образом, разработанная нами схема получения и очистки двухдоменных лакказ позволяет получать белок с высоким выходом. Стоимость реактивов для получения 1 г ферментного препарата (при выходе 180 мг белка с литра среды) составила 568 р. Поскольку подсчитать расходы на амортизацию оборудования и оплату труда крайне сложно при отсутствии отлаженного производства, в дальнейших расчётах мы приняли данные величины примерно равными стоимости расходных материалов. Таким образом, стоимость одного грамма белка, полученного по представленной схеме, составила 1136 р. 2270 р. Что гораздо ниже стоимости лакказ, реализуемых через торговую площадку Sigma-Aldrich (https://www.sigmaaldrich.com/russian-federation.html).

\section{Заключение}

Результатом данной работы стала оптимизация методики получения активных двухдоменных лакказ с высоким выходом фермента (до 180 мг с литра среды) и низкой себестоимостью конечного продукта (от 1136 р. за 1 г очищенного белкового препарата при выходе белка 180 мг с 1 литра среды).

\section{Исследование выполнено при финансовой поддержке РФФИ в рамках научного проекта № 18-34-00566.}

\section{Список литературы}

1. Baldrian P. // FEMS Microbiol Lett. 2006. Vol. 30. No 2. pp. 215-242.
2. Claus H. // Arch Microbiol. 2003. Vol. 179. No 3. pp. 145-150. 
3. Otto B., Schlosser D. // Planta. 2014. Vol. 240. No 6. pp. 1225-1236.

4. Lisov A.V., Zavarzina A.G., Zavarzin A.A., Leontievsky A.A. // FEMS Microbiol Lett. 2007. Vol. 275. No 1. pp. 46-52.

5. Thurston C.F. // Microbiology. 1994. Vol. 140. pp. 19-26.

6. Sterjiades R., Dean J.F., Eriksson K.E. // Plant Physiol. 1992. Vol. 99. No 3. pp. 11621168.

7. Endo K., Hosono K., Beppu T., Ueda K. // Microbiology. 2002. Vol. 148. pp. 1767-1776.

8. Lu L., Zeng G., Fan C., Zhang J. et al. // Appl Environ Microbiol. 2014. Vol. 80. No 11. pp. 3305-3314.

9. Minussi R.C., Pastore G.M., Duran N. // Trends Food Sci Tech. 2002. Vol. 13. No 6-7. pp. 205-216.
10. Dominguez A., Couto S.R., Sanroman M.A. // World J Microbiol Biotechnol. 2005. Vol. 21. No 4. pp. 405-409.

11. Couto S.R., Herrera J.L.T. // Biotechnol Adv. 2006. Vol. 24. No 5. pp. 500-513.

12. Trubitsina L.I., Tishchenko S.V., Gabdulkhakov A.G., Lisov A.V. et al. // Biochimie. 2015. Vol. 112. pp. 151-159.

13. Tishchenko S., Gabdulkhakov A., Trubitsina L., Lisov A. et al. // Acta Crystallogr F Struct Biol Commun. 2015. Vol. 71. pp. 12001204.

14. Lisov A.V., Trubitsina L.I., Lisova Z.A., Trubitsin I.V. et al. // Process biochemistry. 2019. Vol. 76. pp. 128-135.

15. Durao P., Chen Z., Fernandes A.T., Hildebrandt P. et al. // J Biol Inorg Chem. 2008. Vol. 13. No 2. pp. 183-193.

16. Gunne M., Urlacher V.B. // PLoS One. 2012. Vol. 7. No 12. pp. e52360.

\title{
Optimization of the recombinant two-domain laccases producing process
}

\author{
Trubitsina Liubov’ I., Trubitsin Ivan V., Lisov Alexander V.
}

Skryabin Institute of Biochemistry and Physiology of Microorganisms RAS, FSBI of Science «Federal Research Center «Pushchino Scientific Center for Biological Research of the Russian Academy of Sciences», Pushchino

Laccases (EC 1.10.3.2) belong to the family of copper-containing oxidases and contain four copper atoms in their active centre. Laccases can oxidise a broad range of organic and inorganic compounds. Enzymes of this class are used in different biotechnological processes (paper and pulp, textile, food industries) and can be structurally divided into two groups: two-domain (2D) and three-domain (3D) enzymes. Common properties of 2D laccases are resistance to specific inhibitors of copper-containing oxidases and high thermal stability. 2D laccases have lower redox potential as compared to three-domain enzymes. However, it can be increased by using redox mediators. High thermal stability and resistance to inhibitors are important criteria for the selection of enzymes for biotechnology. Another important criterion for the biotechnology-relevant enzymes is the cost of their production. If obtaining an enzyme requires significant costs, and the yield of the final product is low, the production of the enzyme is impractical.

Therefore, the aim of this work is to optimise the process of production of 2D recombinant laccases expressed heterologously in the Escherichia coli strain, and to calculate the cost of the final product (using the SgfSL, SvSL, and SaSL enzymes obtained in our laboratory as an example). Previously, three recombinant two-domain laccases were cloned and expressed in the Escherichia coli strain M15 (pRep4). In this study we examined the effect of various factors on the maximal yield of laccases: the effect of copper ions, the effect of inductor concentration, cultivation conditions, optical density of the culture, and other conditions. It was shown that the optimal concentration of copper ions is $1 \mathrm{mM}$ while the optimal concentration of inductor IPGT is $0.1 \mathrm{mM}$ (the laccase aggregation effect was absent and a high laccase yield was observed). We confirmed the conclusions of our colleagues that microaerobic conditions are required for obtaining laccases maximally saturated with copper ions. Without the stage of microaerobic growth, the specific activity of the purified enzymes decreases by 2 times. It was found that if the rate of cell stirring during the induction of enzyme synthesis is too high, it leads to the aggregation of enzymes. The stirring rate at which laccases do not aggregate is 50-100 rpm. As a result, a process of production of two-domain bacterial recombinant laccases was developed and optimised. The maximum yield of enzymes was up to $180 \mathrm{mg}$ of protein per liter of medium. The enzyme had a low production cost (16-32 euros per $1 \mathrm{~g}$ of protein).

Keywords: two-domain laccase, enzyme, purification, affinity chromatography. 


\section{References}

1. Baldrian P., FEMS Microbiol Lett., 2006, Vol. 30, No 2, pp. 215-242. DOI: 10.1111/j.1574-4976.2005.00010.x. Available at: https://onlinelibrary.wiley.com/ (accessed 16.12.2019).

2. Claus H., Arch Microbiol., 2003, Vol. 179, No 3, pp. 145-150. DOI: 10.1007/s00203-0020510-7. Available at: https://link.springer.com/ (accessed 16.12.2019).

3. Otto B., Schlosser D., Planta, 2014, Vol. 240, No 6, pp. 1225-1236. DOI: 10.1007/s00425-014-2144-9. Available at: https://link.springer.com/ (accessed 16.12.2019).

4. Lisov A.V., Zavarzina A.G., Zavarzin A.A., Leontievsky A.A., FEMS Microbiol Lett, 2007, Vol. 275, No 1, pp. 46-52. DOI: 10.1111/j.1574-6968.2007.00858.x. Available at: https://academic.oup.com/femsle (accessed 16.12.2019).

5. Thurston C.F., Microbiology, 1994, Vol. 140, pp. 19-26.

6. Sterjiades R., Dean J.F., Eriksson K.E., Plant Physiol., 1992, Vol. 99, No 3, pp. 11621168. DOI: $10.1104 / p p .99 .3 .1162$. Available at: http://www.plantphysiol.org/

(accessed 16.12.2019).

7. Endo K., Hosono K., Beppu T., Ueda K., Microbiology, 2002, Vol. 148, pp. 1767-1776. DOI: 10.1099/00221287-148-6-1767. Available at: https://www.microbiologyresearch.org/ (accessed 16.12.2019).

8. Lu L., Zeng G., Fan C., Zhang J. et al., Appl Environ Microbiol, 2014, Vol. 80, No 11, pp. 3305-3314. DOI: 10.1128/AEM.00223-14. Available at: https://aem.asm.org/ (accessed 16.12.2019)

9. Minussi R.C., Pastore G.M., Duran N., Trends Food Sci Tech, 2002, Vol. 13, No 6-7, pp. 205-216.

Трубицина Любовь Игоревна - к.б.н., младший научный сотрудник, лаборатория микробной энзимологии, ИБФМ РАН ФИЦ ПНЦБИ РАН, Пущино

Трубицин Иван Васильевич - к.б.н., научный сотрудник, лаборатория микробной энзимологии, ИБФМ РАН ФИЦ ПНЦБИ РАН, Пущино

Лисов Александр Викторович - заместитель директора по научной работе ИБФМ РАН, ФИЦ ПНЦБИ РАН, Пущино. Преподаватель ФГБОУ ВО ПушГЕНИ, Пущино
10. Dominguez A., Couto S.R., Sanroman M.A., World J Microbiol Biotechnol., 2005, Vol. 21, No 4, pp. 405-409. DOI 10.1007/s11274-004-1763-x. Available at: https://link.springer.com/ (accessed

16.12.2019).

11. Couto S.R., Herrera J.L.T., Biotechnol $A d v$., 2006, Vol. 24, No 5, pp. 500-513. DOI: 10.1016/j.biotechadv.2006.04.003. Available at: https://www.sciencedirect.com/ (accessed 16.12.2019).

12. Trubitsina L.I., Tishchenko S.V., Gabdulkhakov A.G., Lisov A.V. et al., Biochimie, 2015, Vol. 112, pp. 151-159. DOI: 10.1016/j.biochi.2015.03.005. Available at: https://www.sciencedirect.com/ (accessed 16.12.2019).

13. Tishchenko S., Gabdulkhakov A., Trubitsina L., Lisov A. et al., Acta Crystallogr F Struct Biol Commun., 2015, Vol. 71, pp. 12001204. DOI: $10.1107 / \mathrm{S} 2053230 \mathrm{X} 15014375$. Available at: http://journals.iucr.org/f/ (accessed 16.12.2019).

14. Lisov A.V., Trubitsina L.I., Lisova Z.A., Trubitsin I.V. et al., Process biochemistry, 2019, Vol. 76, pp. 128-135. https://doi.org/10.1016/j.procbio.2018.11.001.

Available at: https://www.sciencedirect.com/ (accessed 16.12.2019).

15. Durao P., Chen Z., Fernandes A.T., Hildebrandt P. et al., J Biol Inorg Chem., 2008, Vol. 13, No 2, pp. 183-193. DOI 10.1007/s00775007-0312-0. Available at: https://link.springer.com/ (accessed 16.12.2019).

16. Gunne M., Urlacher V.B., PLoS One, 2012, Vol. 7, No 12, pp. e52360. DOI: 10.1371/journal.pone.0052360. Available at: https://journals.plos.org/plosone/ accessed 16.12.2019).

Trubitsina Liubov I. - PhD (Bio.), junior researcher, laboratory of microbe enzymology, IBPM RAS PSCBR RAS, Pushchino, e-mail: lyubovyurevich@mail.ru

Trubitsin Ivan V. - PhD (Bio.), researcher, laboratory of microbe enzymology, IBPM RAS PSCBR RAS, Pushchino

Lisov Alexander V. - Deputy Director for Research, IBPM RAS PSCBR RAS, Pushchino. Lecturer of Pushchino State Institute of Natural Science, Pushchino 